\title{
dspace.vutbr.cz
}

\section{The use of numerical simulation \\ for the evaluation of special transparent glass resistance}

BINAR, T.; ŠVARC, J.; VYROUBAL, P.; KAZDA, T.; ROLC, S.; DVOŘÁK, A.; DOSTÁL, P.

Engineering Failure Analysis

2018, vol. 91, September 2018, pp. 433-449

ISSN: $1350-6307$

DOI: https://doi.org/10.1016/j.engfailanal.2018.04.014

Accepted manuscript

(C) 2018. This manuscript version is made available under the CC-BY-NC-ND 4.0 license (http://creativecommons.org/licenses/by-nc-nd/4.0/), doi: https://doi.org/10.1016/j.engfailanal.2018.04.014

Final version available from

https://www.sciencedirect.com/science/article/pii/S0043164818303193 


\section{Accepted Manuscript}

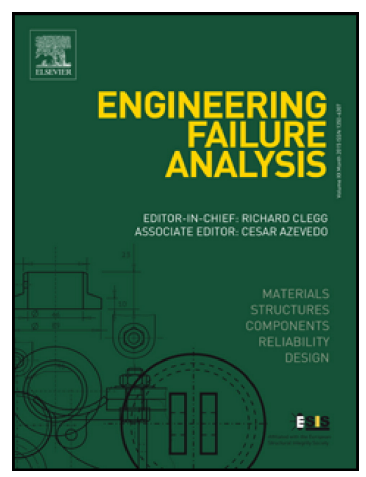

Tomáš Binar, Jiří Švarc, Petr Vyroubal, Tomáš Kazda, Stanislav Rolc, Aleš Dvořák, Petr Dostál

PII: $\quad$ S1350-6307(17)30997-4

DOI: $\quad$ doi:10.1016/j.engfailanal.2018.04.014

Reference: $\quad$ EFA 3442

To appear in: $\quad$ Engineering Failure Analysis

Received date: $\quad 18$ August 2017

Revised date: $\quad 30$ March 2018

Accepted date: $\quad 11$ April 2018

Please cite this article as: Tomáš Binar, Jiř́ Švarc, Petr Vyroubal, Tomáš Kazda, Stanislav Rolc, Aleš Dvořák, Petr Dostál, The use of numerical simulation for the evaluation of special transparent glass resistance. The address for the corresponding author was captured as affiliation for all authors. Please check if appropriate. Efa(2018), doi:10.1016/ j.engfailanal.2018.04.014

This is a PDF file of an unedited manuscript that has been accepted for publication. As a service to our customers we are providing this early version of the manuscript. The manuscript will undergo copyediting, typesetting, and review of the resulting proof before it is published in its final form. Please note that during the production process errors may be discovered which could affect the content, and all legal disclaimers that apply to the journal pertain. 


\section{The Use of Numerical Simulation for the Evaluation of Special Transparent Glass}

\section{Resistance}

Tomáš Binar ${ }^{a}$, Jiř́i Švarc ${ }^{a}$, Petr Vyroubal $^{\mathrm{b}}$, Tomáš Kazda ${ }^{\mathrm{b}}$, Stanislav Rolc $^{\mathrm{c}}$, Aleš Dvořák ${ }^{\mathrm{c}}$, Petr Dostál ${ }^{\mathrm{d}}$

${ }^{a}$ Department of Logistics, University of Defence, Kounicova 65, Brno, Czech Republic

${ }^{b}$ Brno University of Technology, Department of Electrical and Electronic Technology,

Technická 10, Brno, Czech Republic

${ }^{c}$ Military Research Institute, Veslařská 230, Brno, Czech Republic

${ }^{d}$ Department of Technology and Automobile Transport, Mendel University in Brno,

Zemédělská 1, Brno, Czech Republic

E-mail address: kazda@feec.vutbr.cz 


\begin{abstract}
The paper is concerned with the use of numerical simulation for the evaluation of projectile interaction with an assembly composed of multiple materials (transparent armour). For the purpose of assessing the reliability of theoretical numerical models, LS-Dyna explicit solver was employed allowing the evaluation of the projectile interaction effect on the experiment material tested. The material parameters for the numerical simulations were obtained at the temperature of $20{ }^{\circ} \mathrm{C}$. The research objective was to evaluate the projectile interaction with an assembly composed of multiple materials at the temperatures of $-32{ }^{\circ} \mathrm{C}$ and $55^{\circ} \mathrm{C}$, and to evaluate the scope of damage, the delamination of individual layers of transparent armour and the depth of projectile penetration at Protection Level 2 [PARTIAL] (7.62 mm x 39 API BZ) a Level 3 (only projectile $7.62 \mathrm{~mm}$ x 54R B32 API).
\end{abstract}

\title{
Keywords
}

Visco-plasticity, Fringe level, Numerical simulation, Transparent armour life cycle, Projectile 


\section{Introduction}

Transparent areas, i.e. vehicle windows, can be made of composite armour, having several layers of glass, between which highly resistant and elastic polyvinyl butyral (PVB) foils are inserted, and the entire "sandwich" is pressed using a special technology. The disadvantage of the composite laminates is their high weight; the advantage is a relatively low price. Also, polycarbonate sheets, commercially known as Lexgard, are used. Composite polycarbonate sheets can be half the weight and by one third thinner than common composite glass while maintaining the same ballistic resistance properties. At the same time, they exhibit considerably lower transmission of sound, and provide the troops inside a vehicle with better acoustic comfort. Mostly, the combination of both these alternatives, i.e. the outer layer being the glass, the inner layer being the polycarbonate, is used. Such transparent armour has better optical properties and higher resistance to scratching. Industrially produced sapphire is even more advanced in terms of optical properties and resistance to pressure, which is many times higher than in common transparent armours. When special requirements are made for a higher resistance to a pressure wave, transparent armours composed of glass or sapphire at the top and polycarbonate at the bottom with an air gap between the layers are used. Openings in the top and bottom parts of individual windows provide for the release of pressure from the gap between the layers thus rapidly decreasing the stress in the bottom layers. [1][2]

The impact energy absorption and materials allowing or participating in the absorption are highly important in particular in case of unplanned impact loading caused by e.g. car crash or blast. Unfortunately, these dangerous situations are rather common and can result in financial loss, injuries and even casualties. Therefore, the research and development of materials allowing active absorption of a part of the impact energy is crucial for the enhancement of safety in a number of areas and technologies. Detail knowledge of the behaviour of high-speed loaded materials is essential so that protection structures and materials these are made of can be designed sophisticatedly. [1]

\section{Behaviour of impact-loaded materials}


In the tests of mechanical properties, material behaviour is evaluated when loading the material by external forces. Examined properties are including but not limited to:

- strength, i.e. the material resistance to cohesion failure when loading the material by external forces;

- hardness, i.e. the material resistance to surface layers strain due to external forces;

- toughness, i.e. the material resistance to failure when strained by external forces;

- elasticity, i.e. the material capability of restoring to its original shape and dimensions after external forces cease to act.

Within the research and development of absorption materials, advanced structures absorbing impact energy and materials primarily participating in the absorption have been devised. These are special composite materials comprising polyurethane binder and two types of fillers - ceramic aggregate and expanded glass granulate. The materials are intended to be used in the anti-terrorist systems for the civil population protection. The material capability of absorbing a projectile was verified by means numerical calculations. The functionality of the structures and materials designed was confirmed by practical tests.[3]

The transparency together with high compression strength allows using the transparent armour in a wide range of applications as a carrying element loaded by compression and bending. Tensile strength values are lower and oscillating, and in certain cases they decrease with the loading duration.

\subsection{Viscoelasticity}

Viscoelasticity is related to the materials capability of damping mechanical vibrations. Let us consider harmonic dynamic loading (i.e. tensile and compressive loading alternately) of a material within the zone of elastic strain. With such loading, stress and engineering strain generally change with time. The engineering strain $\varepsilon(\mathrm{t})$ has a certain phase lag with regard to the stress $\sigma(\mathrm{t})$. This is caused by the structural materials damping causing partial transformation of the mechanical energy into heat. This is the case of internal material damping. The amount of dissipated energy is the measure of the structural damping. Materials are classified as elastic, viscoelastic and viscous based on the energy dissipation during dynamic loading.[4][5]

Unlike purely elastic substances, a viscoelastic substance has an elastic component and a viscous component. The viscosity of a viscoelastic substance gives the substance a strain rate 
dependence on time. Purely elastic materials do not dissipate energy (heat) when a load is applied, then removed. However, a viscoelastic substance loses energy when a load is applied, then removed. Hysteresis is observed in the stress-strain curve, with the area of the loop being equal to the energy lost during the loading cycle. Since viscosity is the resistance to thermally activated plastic deformation, a viscous material will lose energy through a loading cycle. Plastic deformation results in lost energy, which is uncharacteristic of a purely elastic material's reaction to a loading cycle.[6]

Specifically, viscoelasticity is a molecular rearrangement. When a stress is applied to a viscoelastic material such as a polymer, parts of the long polymer chain change positions. This movement or rearrangement is called creep. Polymers remain a solid material even when these parts of their chains are rearranging in order to accompany the stress, and as this occurs, it creates a back stress in the material. When the back stress is the same magnitude as the applied stress, the material no longer creeps. When the original stress is taken away, the accumulated back stresses will cause the polymer to return to its original form. The material creeps, which gives the prefix visco-, and the material fully recovers, which gives the suffix elasticity.[7]

\subsection{Model Johnson-Cook (JC)}

The most commonly used constitutive equation describing the behaviour of impactloaded metals is the Johnson-Cook model:

$$
\sigma_{\mathrm{y}}\left(\varepsilon_{\mathrm{p}}, \dot{\varepsilon}_{\mathrm{p}}, \mathrm{T}\right)=\left[\mathrm{A}+\mathrm{B}\left(\varepsilon_{\mathrm{p}}\right)^{\mathrm{n}}\right]\left[1+\operatorname{Cln}\left(\dot{\varepsilon}_{\mathrm{p}}^{*}\right)\right]\left[1-\left(\mathrm{T}^{*}\right)^{\mathrm{m}}\right]
$$

where $\varepsilon_{\mathrm{p}}$ is the equivalent plastic strain, $\dot{\varepsilon}_{\mathrm{p}}$ is the plastic strain-rate and $\dot{\varepsilon}_{\mathrm{p}}{ }^{*}$ is the normalized strain-rate calculated as:

$$
\dot{\varepsilon}_{\mathrm{p}}^{*}=\frac{\dot{\varepsilon}_{\mathrm{p}}}{\dot{\varepsilon}_{\mathrm{p} 0}}
$$

where $\dot{\varepsilon}_{\mathrm{p} 0}$ is the effective plastic strain-rate of the quasi-static test used to determine the yield and hardening parameters $\mathrm{A}, \mathrm{B}$ and $\mathrm{n}$.

$\mathrm{A}, \mathrm{B}, \mathrm{C}, \mathrm{n}, \mathrm{m}$ are the material parameters, $\varepsilon_{\mathrm{p}}$ is the effective plastic strain, $\mathrm{T}^{*}$ is the homologous temperature. 


\subsection{The behaviour of strained brittle materials}

Johnson and Holmquist created two constitutive models of strain and fracture behaviour of brittle materials, referred to in reference literature as $\mathrm{JH}-1$ and $\mathrm{JH}-2$. In the respective numerical simulations, the latter model, referred to as JH-2, was applied.[4] The model comprises the strength, pressure and damage. The ceramics strength (equivalent stress) is expressed as follows:

$$
\sigma^{*}=\sigma_{i}^{*}-D\left(\sigma_{i}^{*}-\sigma_{f}^{*}\right)
$$

where

$$
\sigma_{i}^{*}=A\left(P^{*}+T^{*}\right)^{N}\left(1+C \ln \dot{\varepsilon}^{*}\right)
$$

represents the behaviour of intact material.

In the constitutive relationship both intact and fractured materials are included. The damage is described in D parameter with its value ranging from zero to one. For the intact material, its value is 0 , and for fully damaged material, its value is 1.[8] Accumulated damage is then calculated as:

$$
\mathrm{D}=\sum \frac{\Delta \varepsilon^{\mathrm{p}}}{\varepsilon_{\mathrm{f}}^{\mathrm{p}}}
$$

where $\Delta \varepsilon^{\mathrm{p}}$ is the plastic strain in one integration cycle, and $\varepsilon_{\mathrm{f}}^{\mathrm{p}}$ is the strain at fracture at constant pressure.

$$
\varepsilon_{\mathrm{f}}^{\mathrm{p}}=\mathrm{d}_{1}\left(\mathrm{P}^{*}+\mathrm{T}^{*}\right)^{\mathrm{d}_{2}}
$$

The following formula describes the behaviour of the damaged material:

$$
\sigma_{\mathrm{f}}^{*}=\mathrm{B}\left(\mathrm{P}^{*}\right)^{\mathrm{m}}\left(1+\mathrm{Cln} \dot{\varepsilon}^{*}\right) \leq \mathrm{SFMAX}
$$

The pressure increment can be determined from energetic considerations - refer to (Johnson and Holmquist 1994, Holmquist et al. 2001).

\section{Numerical model}

For the purpose of the analysis, the LS-DYNA finite element system was used. It allows evaluating the reliability of theoretical numerical models in a specific application of the impact of a pressure wave on an assembly composed of multiple materials. This type of application is suitable for a numerical solution using a so-called explicit method. Basic 
equations of the explicit dynamic analysis express the balance of weights, moments and energies in Lagrangian coordinates. These equations together with the material model, a set of initial and boundary conditions describe the complete solution of the analysis.[8]

Partial differential equations express the balance of moments related to the acceleration in relation to the elastic stress tensor $\sigma_{\mathrm{ij}}$ :

$$
\begin{aligned}
& \rho \ddot{x}=b_{x}+\frac{\partial \sigma_{x x}}{\partial x}+\frac{\partial \sigma_{x y}}{\partial y}+\frac{\partial \sigma_{x z}}{\partial z} \\
& \rho \ddot{y}=b_{y}+\frac{\partial \sigma_{y x}}{\partial x}+\frac{\partial \sigma_{y y}}{\partial y}+\frac{\partial \sigma_{y z}}{\partial z} \\
& \rho \ddot{z}=b_{z}+\frac{\partial \sigma_{z x}}{\partial x}+\frac{\partial \sigma_{z y}}{\partial y}+\frac{\partial \sigma_{z z}}{\partial z}
\end{aligned}
$$

The equilibrium of energies is calculated as follows:

$$
\dot{\mathrm{e}}=\frac{1}{\rho}\left(\sigma_{\mathrm{xx}} \dot{\varepsilon}_{\mathrm{xx}}+\sigma_{\mathrm{yy}} \dot{\varepsilon}_{\mathrm{yy}}+\sigma_{\mathrm{zz}} \dot{\varepsilon}_{\mathrm{zz}}+2 \sigma_{\mathrm{xy}} \dot{\varepsilon}_{\mathrm{xy}}+2 \sigma_{\mathrm{yz}} \dot{\varepsilon}_{\mathrm{yz}}+2 \sigma_{\mathrm{zx}} \dot{\varepsilon}_{\mathrm{zx}}\right)
$$

In each time step, these equations are explicitly set pro each element based on the input values and the result of the previous time step. It is only the balance of weights and moments that is enforced. The balance of weights, moments and energies can only be reached in well conditioned tasks. The equilibrium of energies is continuously monitored for the purpose of checking and maintaining the solution quality (as opposed to the convergence of implicit solution). [2][9]

The explicit analysis solution is particularly suitable for the simulations of high-speed events, impacts of bodies where large element deformations are included. Also, it easily allows including the material erosion. This model was successfully employed to set the properties of ceramic materials and composed laminates.[10]

\subsection{Task model}

All simulations were solved as multihit, i.e. the simulations were carried out for two consecutive projectile hits at a predefined distance.

Using the Finite Element Method (FEM), a transparent armour simulation model was created for multihit by two projectiles at a predefined distance.

For the Protection Level K2, as per STANAG AEP-55, Volume 1, projectile $7.62 \mathrm{~mm} \mathrm{x}$ 39 API BZ was used with the impact velocity of $695 \mathrm{~m} / \mathrm{s}$. The projectile was composed of a 
hardened steel core and a bronze jacket. For the Protection Level K3, as per STANAG AEP55, Volume 1, projectile $7.62 \mathrm{~mm} \times 54 \mathrm{R}$ B32 API was used with the initial velocity of $854 \mathrm{~m} / \mathrm{s}$. The projectile was composed of a hardened steel core and a bronze jacket. In front of the core point there was soft filling (Fig. 1). 

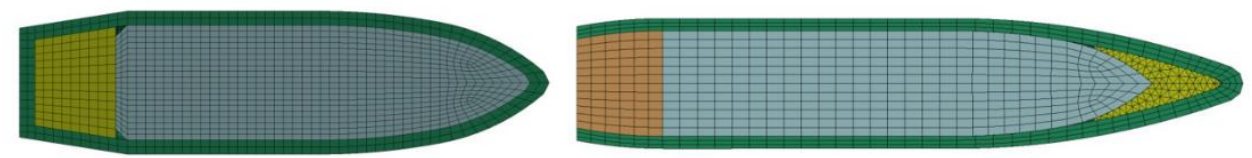

Fig. 1 Finite element method model of projectile $7.62 \mathrm{~mm}$ x 39 API BZ and projectile $7.62 \mathrm{~mm} \times 54 \mathrm{R}$ B32 API. 
For individual protection levels, a 3D finite element model with one symmetry plane was constructed.

The Finite Element Method (FEM) is a numerical method simulating the course of stress, strain, natural frequencies, thermal flows, electromagnetic phenomena, fluid flows etc. using a physical model. Its principle lies in the discretisation of continuous systems to a certain (finite) number of elements; the parameters are identified in individual nodes. The FEM is primarily employed to check designed equipment or to determine the critical (most stressed) point of a structure.[11]

\section{TRANSPARENT ARMOUR}

A numerical model of projectile interaction with the composite transparent armour used in DINGO armoured vehicles was made for the Protection Level 2 [PARTIAL] and Level 3. The scope of damage, the delamination of individual layers and the depth of penetration were examined.

The numerical simulations were made for two armour temperatures, i.e. $-32{ }^{\circ} \mathrm{C}$ and $55^{\circ} \mathrm{C}$.

The composition of the DINGO vehicle transparent armour and the thicknesses of individual layers are shown in Fig. 2 and 3 below. 


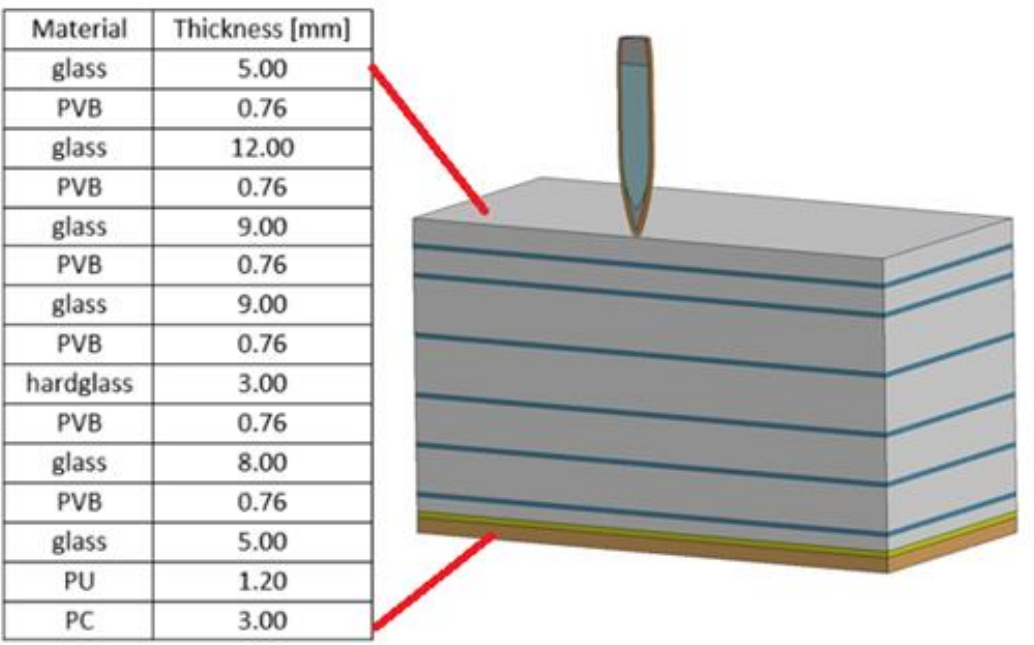

Fig. 2 The composition of DINGO vehicle transparent armour 


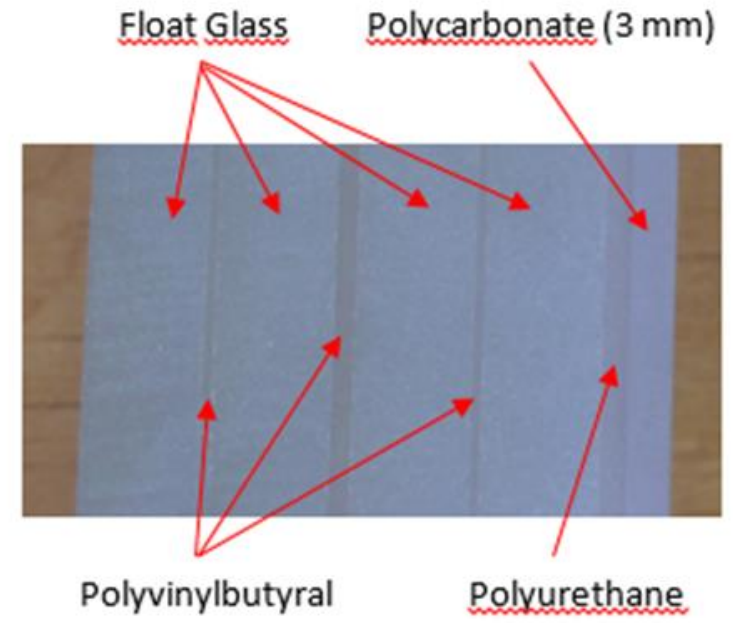

Fig. 3 The composition of armoured vehicle transparent armour 


\section{Results and Discussion}

The numerical model is described using input shapes and theoretical models determined by physical constants.

For individual protection levels, a 3D finite element model with one symmetry plane was constructed. The armour was modelled using a Johnson-Holmquist material model with set failure properties. Polyurethane (PU) a polycarbonate (PC) materials were input by means of an isotropic material model using the stress-strain relationship. Polyvinyl butyral (PVB) was modelled using an elastic model with the elasticity modulus defined in relation to temperature as per in Fig. 4 [12] below and Poisson number 0.49. 


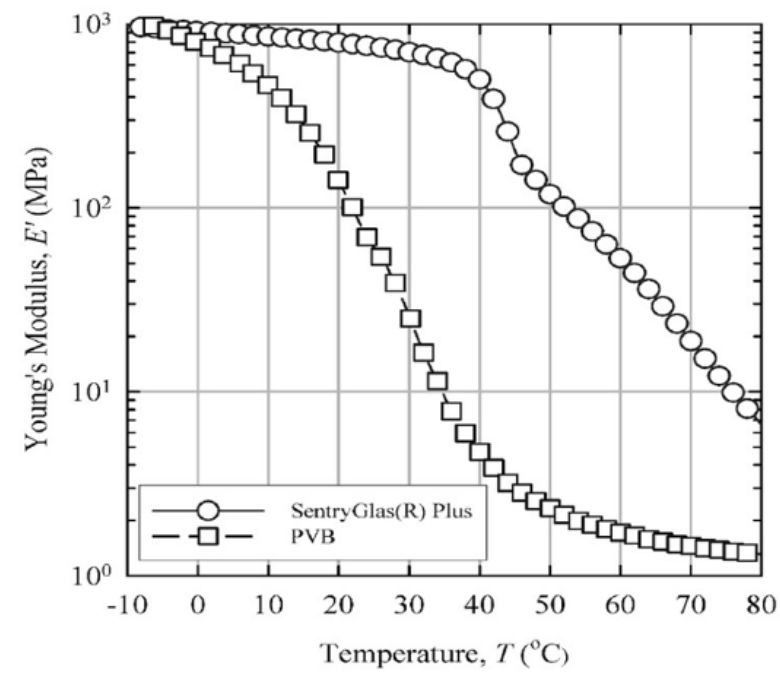

Fig. 4 The PVB material elasticity modulus-temperature relationship.[12] 
In the analyses below, the response of the models behaviour to modifications in these physical properties, in particular material parameters, was examined. This procedure allows precise setting of all material model values and the application of these verified values in further studies.

Using an explicit numerical method, the scope of transparent armour damage by a projectile hit was examined at specific protection levels as per STANAG 4569 AEP-55, Volume 1. The Table 1 below lists the types of projectiles used, along with defined materials, weights and impact velocities . 
TAB. 1 Test projectile types - Protection Levels K2 to K3 STANAG AEP-55, Volume 1.

\begin{tabular}{|c|c|c|c|c|}
\hline Projectile & $\begin{array}{c}\text { Level of } \\
\text { protection }\end{array}$ & $\begin{array}{c}\text { Core } \\
\text { material }\end{array}$ & $\begin{array}{c}\text { Projectile weight } \\
{[\mathrm{g}]}\end{array}$ & $\begin{array}{c}\text { Projectile velocity } \\
{[\mathrm{m} / \mathrm{s}]}\end{array}$ \\
\hline $\begin{array}{c}7.62 \mathrm{~mm} \times \text { 39 API } \\
\text { BZ }\end{array}$ & K2 & Steel & 7.77 & 695 \\
\hline $\begin{array}{c}7.62 \mathrm{~mm} \text { x 54R B32 } \\
\text { API }\end{array}$ & K3 & Steel & 10.4 & 854 \\
\hline
\end{tabular}




\subsection{Proteciton Level K2 - Dingo vehicle}

For Protection Level 2 [PARTIAL], the numerical simulation was made for two adjacent hits at the distance of $120 \mathrm{~mm}$, Fig. 5 . 


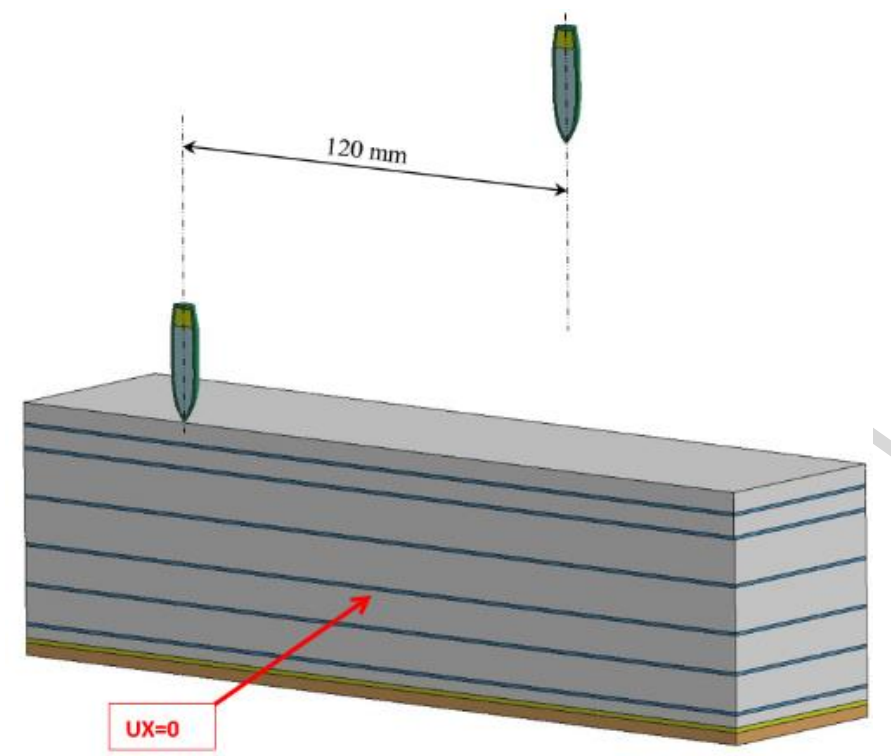

Fig. 5 Finite Element Method model of transparent armour used in DINGO vehicles Protection Level K2. 
In the TAB 2 the number of elements and nodes used for the creation of a mesh of finite elements is stated. 
TAB. 2 No. of nodes and elements in the FE model - multihit K2

\begin{tabular}{|c|c|c|c|c|}
\hline \multirow{2}{*}{ FE model variant } & \multicolumn{2}{|c|}{ Projectile } & \\
\cline { 2 - 5 } & No. of nodes & No. of elements & No. of nodes & No. of elements \\
\hline Protection Level K2 & 23,538 & 18,440 & $1,369,962$ & $1,326,000$ \\
\hline
\end{tabular}


4.1.1. Protection Level $\mathrm{K} 2$ at the temperature of $-32{ }^{\circ} \mathrm{C}$

In the Fig. 6 below, the projectile interaction with transparent armour is shown in relation to time at the constant temperature of $-32{ }^{\circ} \mathrm{C}$. 


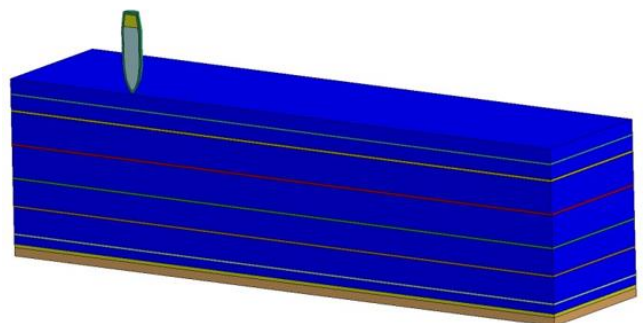

Time $=0.00 \mathrm{~s}$

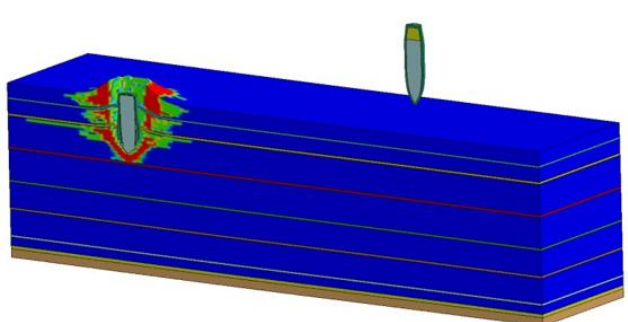

Time $=0.10 \mathrm{~s}$

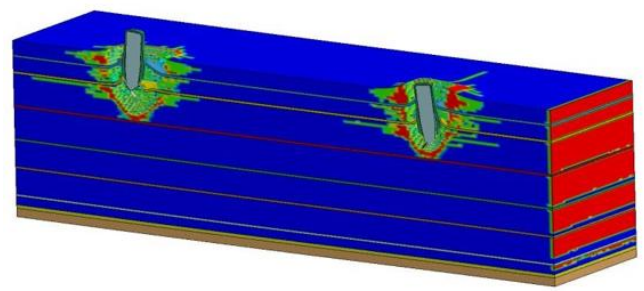

Time $=0.25 \mathrm{~s}$
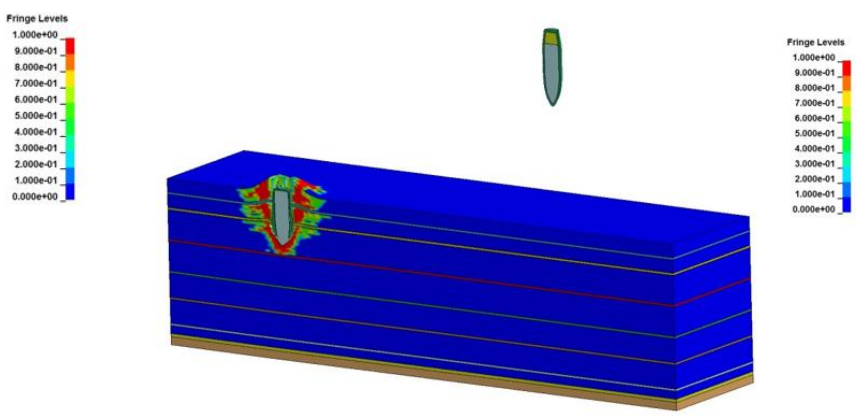

Time $=0.05 \mathrm{~s}$

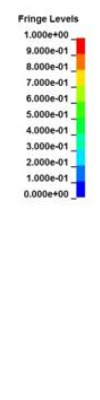

Time $=0.15 \mathrm{~s}$
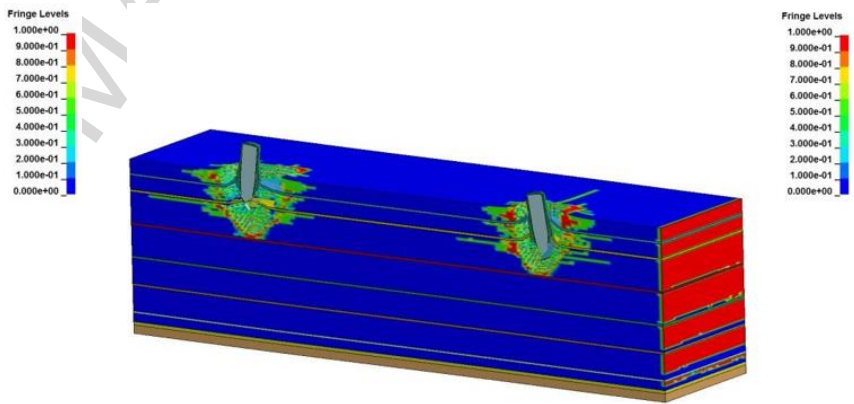

Time $=0.30 \mathrm{~s}$

Fig. 6 The course of projectile penetration into transparent armour at the temperature of -32 ${ }^{\circ} \mathrm{C}$ at different instants of time. 
It follows from the results of the numerical simulation that both the first and the second projectile stopped in the third layer of the armour. The depth of penetration of both the first and the second hit was $21 \mathrm{~mm}$, Fig. 7 and 8. 


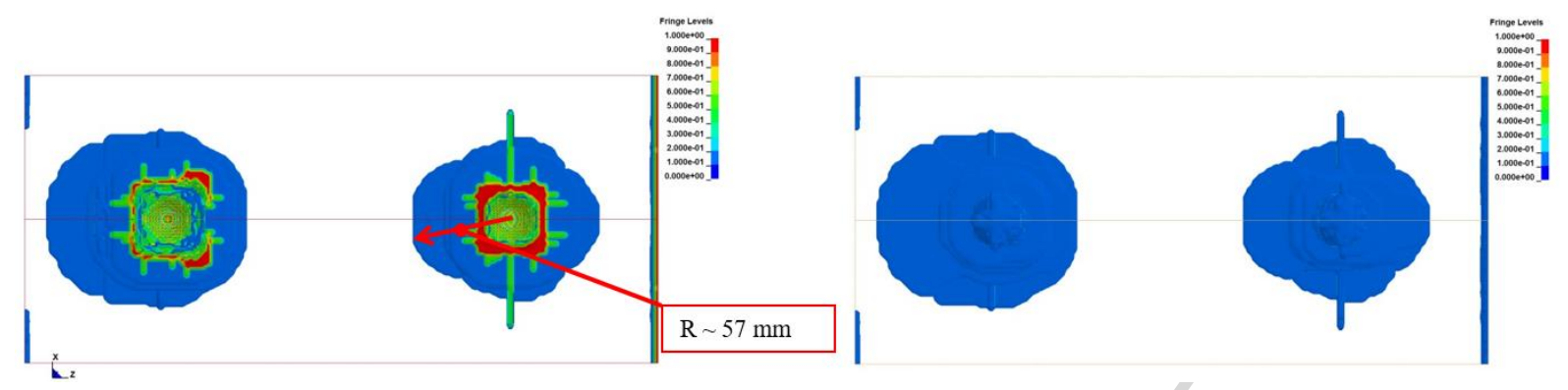

Fig. 7 Armour failure (front side - left) - the first hit on the left, the second hit on the right; armour failure (rear side - right) - the first hit on the left, the second hit on the right. 


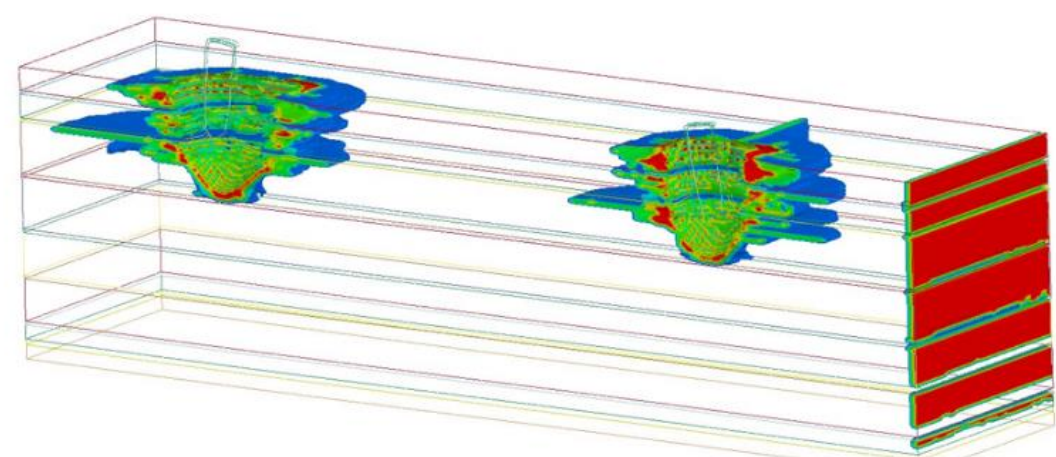

Fig. 8 The transparent armour failure at the temperature of $-32^{\circ} \mathrm{C}$. 


\subsubsection{Protection Level $\mathrm{K} 2$ at the temperature of $+55^{\circ} \mathrm{C}$}

In the Fig. 9 below, the projectile interaction with transparent armour in relation to time is shown at the constant temperature of $+55^{\circ} \mathrm{C}$. 


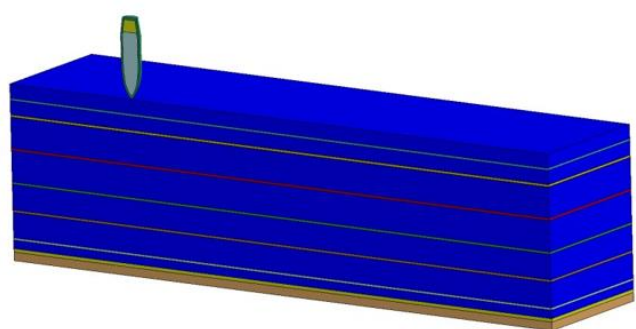

Time $=0.00 \mathrm{~s}$

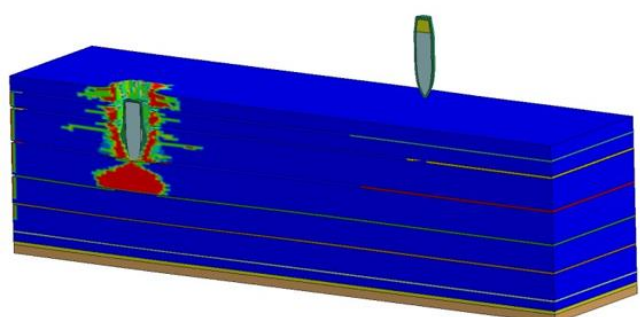

Time $=0.10 \mathrm{~s}$

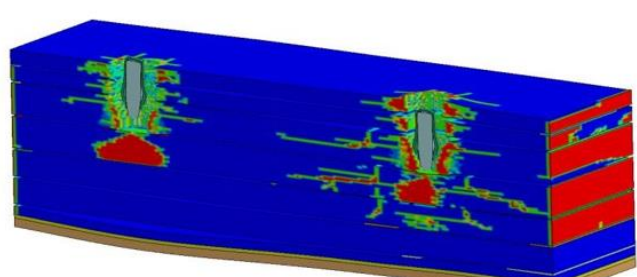

Time $=0.25 \mathrm{~s}$
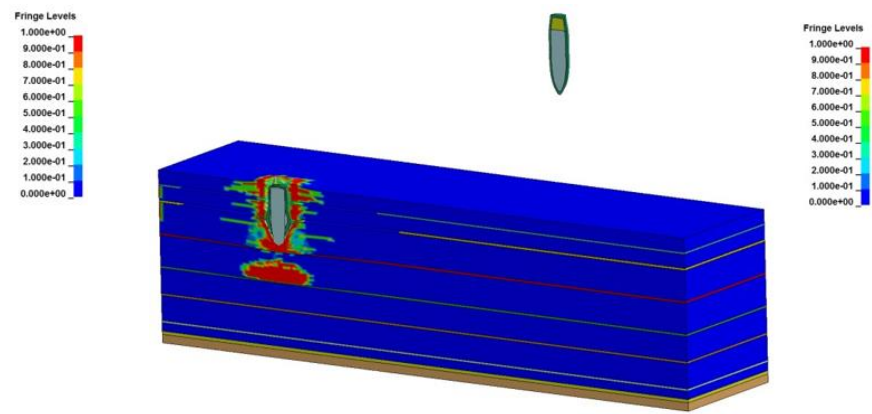

Time $=0.05 \mathrm{~s}$

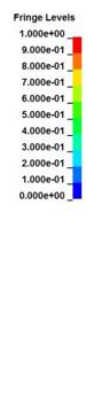

Time $=0.15 \mathrm{~s}$

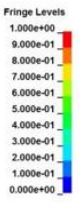

Time $=0.30 \mathrm{~s}$

Fig. 9 The course of projectile penetration into transparent armour at the temperature of +55 ${ }^{\circ} \mathrm{C}$ at different instants of time. 
It follows from the results of the numerical simulation that both the first and the second projectile stopped in the third layer of the armour. The depth of penetration of both the first and the second hit was $24 \mathrm{~mm}$, Fig. 10 and 11. 

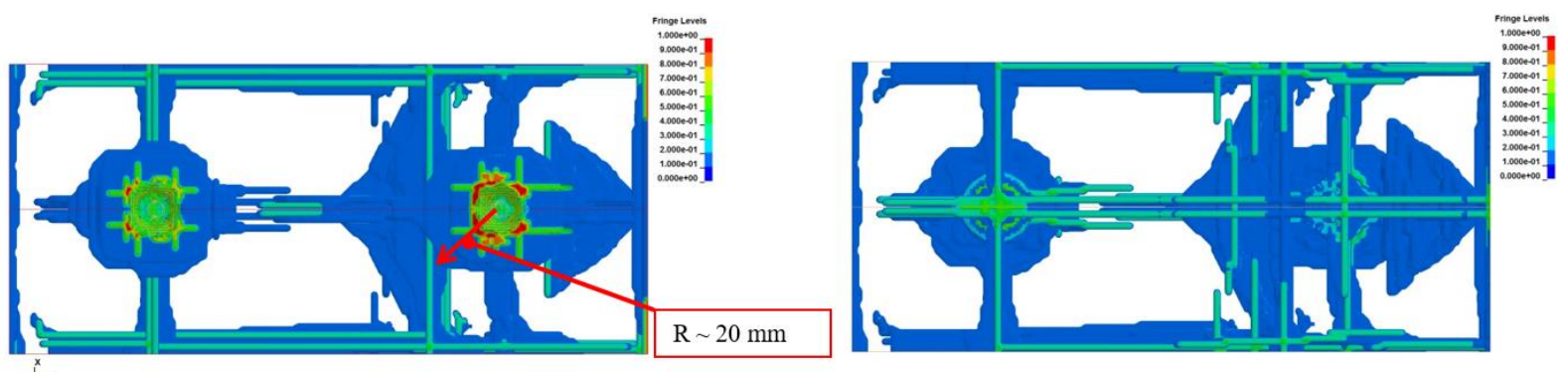

Fig. 10 Armour failure (front side - left) - the first hit on the left, the second hit on the right; armour failure (rear side - right) - the first hit on the left, the second hit on the right. 


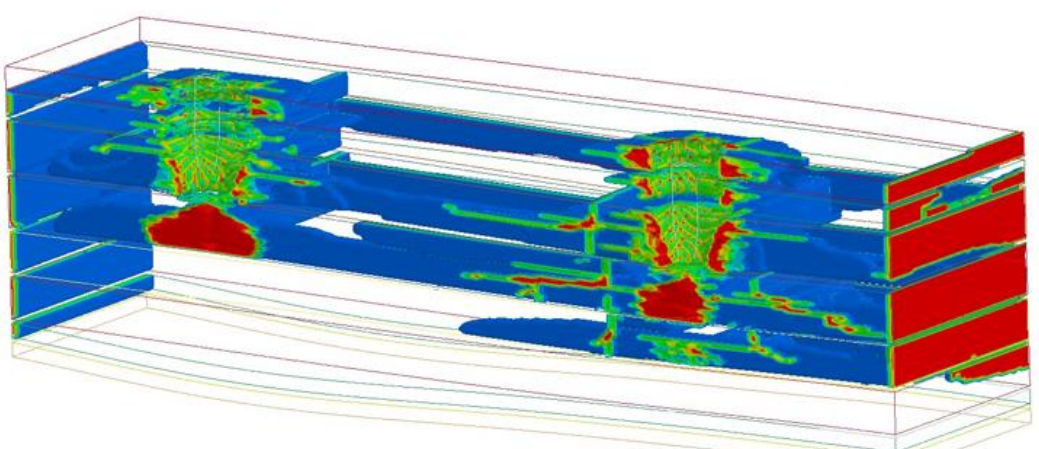

Fig. 11 The transparent armour failure at the temperature of $+55^{\circ} \mathrm{C}$.

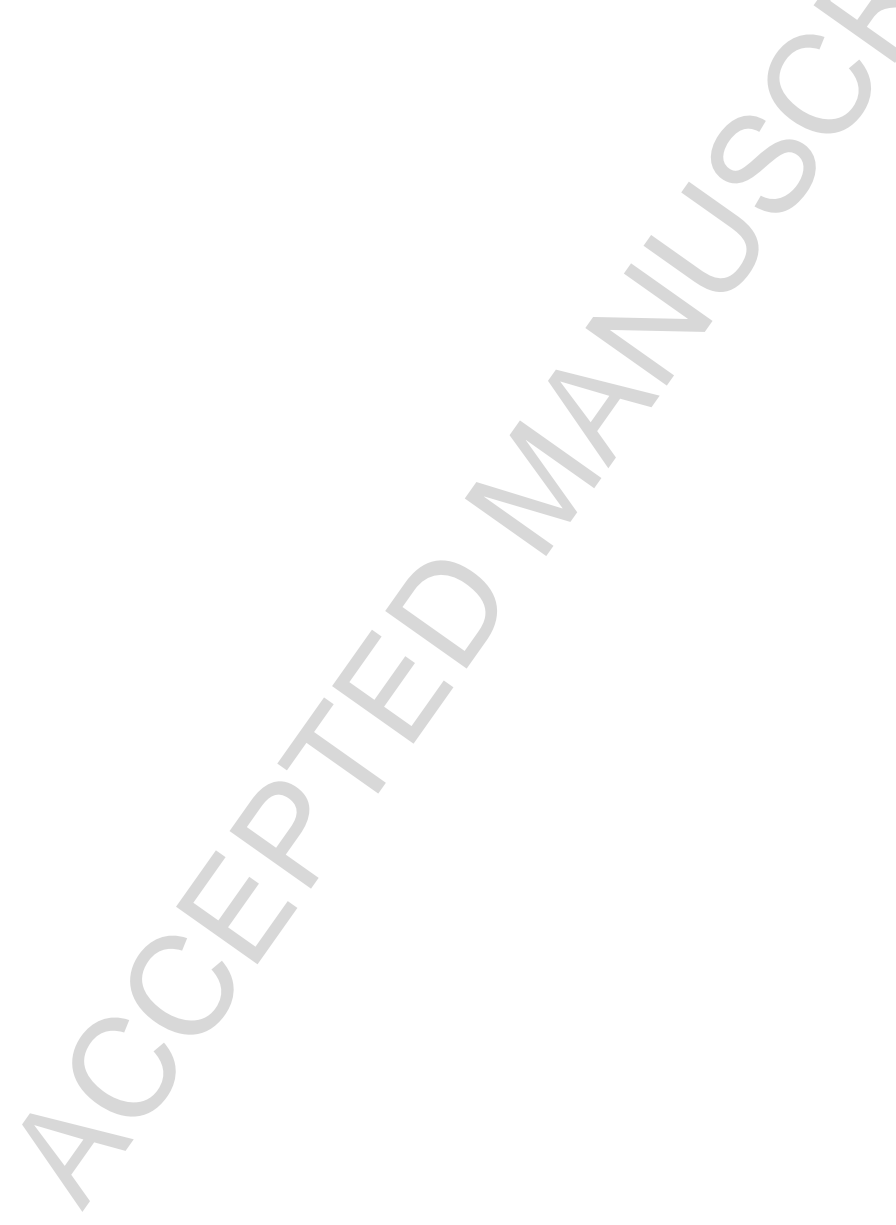




\subsection{Protection Level K3 - Dingo vehicle}

For Protection Level 3, the numerical simulation was made for two adjacent hits at the distance of $500 \mathrm{~mm}$, Fig. 12 and Tab. 3. 


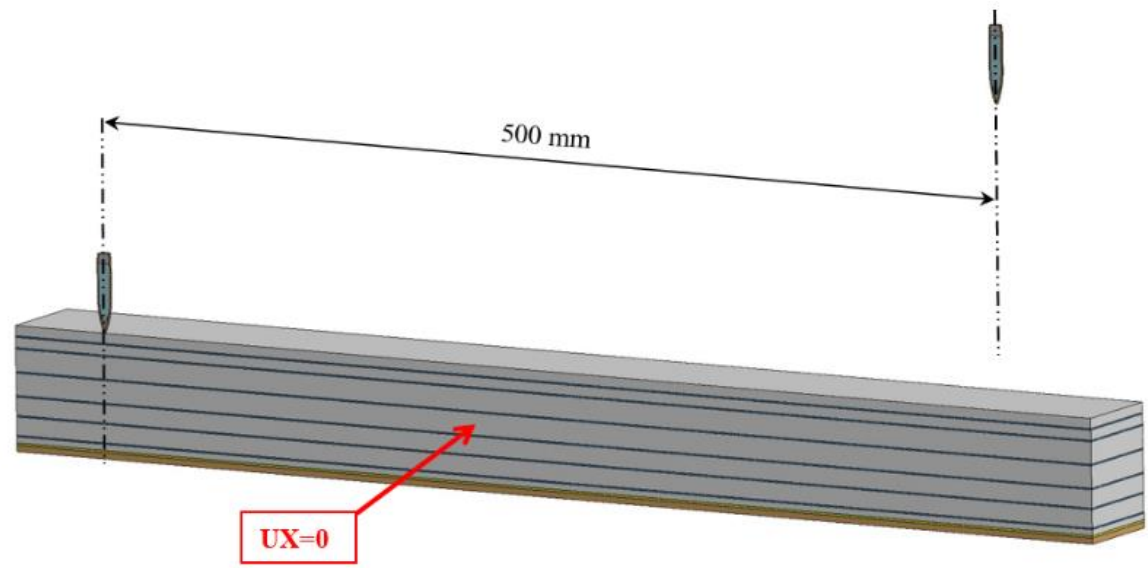

Fig. 12 FE model of transparent armour used in DINGO vehicles - Protection Level K3. 
TAB.3: No. of nodes and elements in the FE model - multihit K3

\begin{tabular}{|c|c|c|c|c|}
\hline \multirow{2}{*}{ FE model variant } & \multicolumn{2}{|c|}{ Projectile } & \\
\cline { 2 - 5 } & No. of nodes & No. of elements & No. nodes & No. of elements \\
\hline Protection Level K3 & 10,282 & 10,412 & $3,708,771$ & $3,600,000$ \\
\hline
\end{tabular}




\subsubsection{Protection Level $\mathrm{K} 3$ at the temperature of $-32{ }^{\circ} \mathrm{C}$}

In the Fig. 13 below, the projectile interaction with transparent armour in relation to time is shown at the constant temperature of $-32{ }^{\circ} \mathrm{C}$ 
Time $=0.00 \mathrm{~s}$

Time $=0.05 \mathrm{~s}$
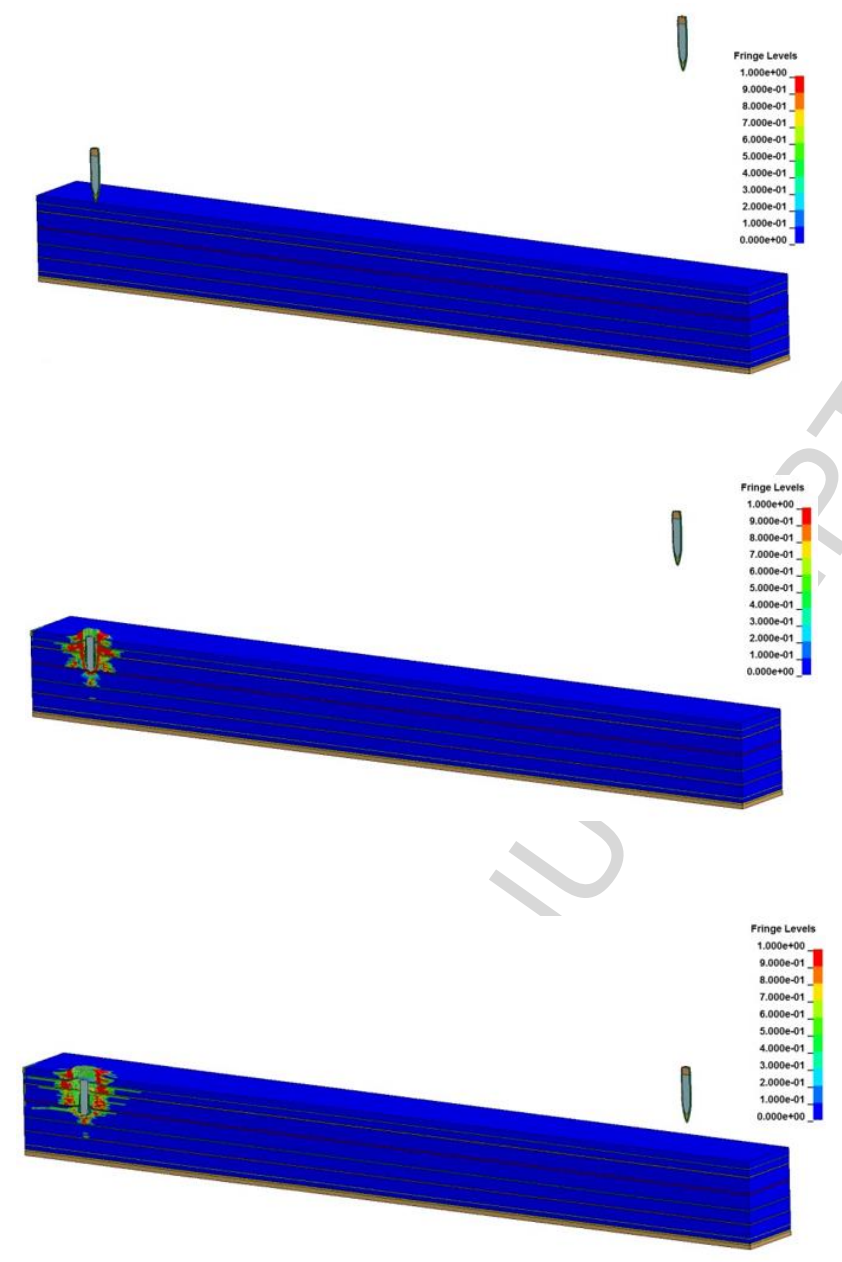

Time $=0.15 \mathrm{~s}$

Time $=0.20 \mathrm{~s}$
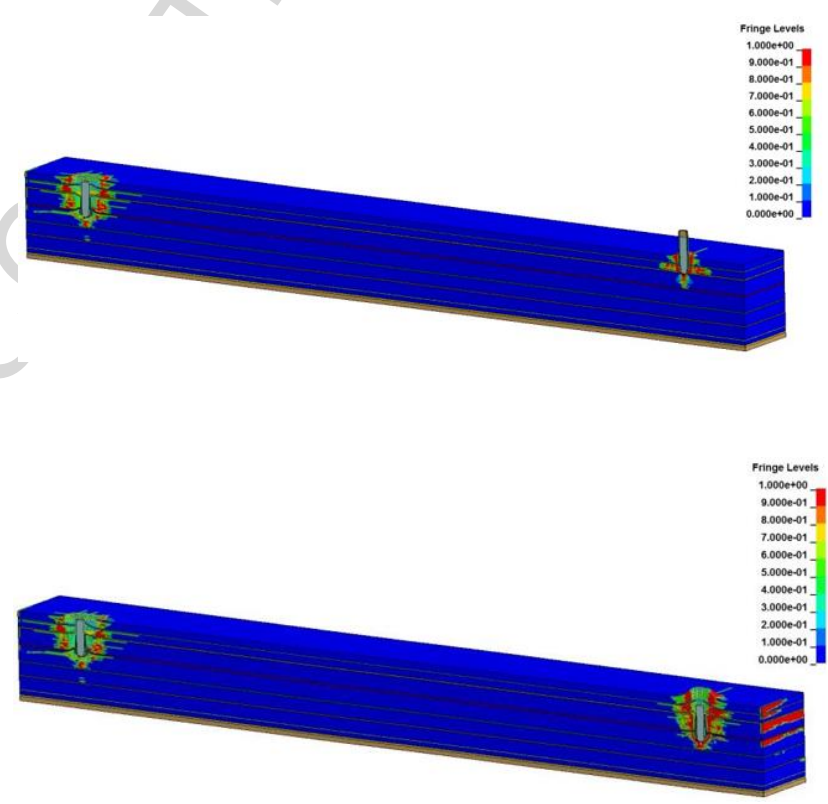

Time $=0.25 \mathrm{~s}$ 


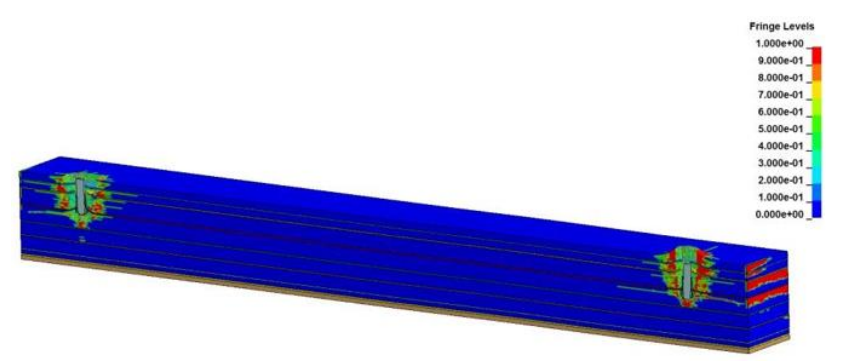

Time $=0.30 \mathrm{~s}$

Fig. 13 The course of projectile penetration into transparent armour at the temperature of $32{ }^{\circ} \mathrm{C}$ at different instants of time. 
It follows from the results of the numerical simulation that both the first and the second projectile stopped in the fourth layer of the armour at the depth of approx. $30 \mathrm{~mm}$, Fig. 14 and 15. 


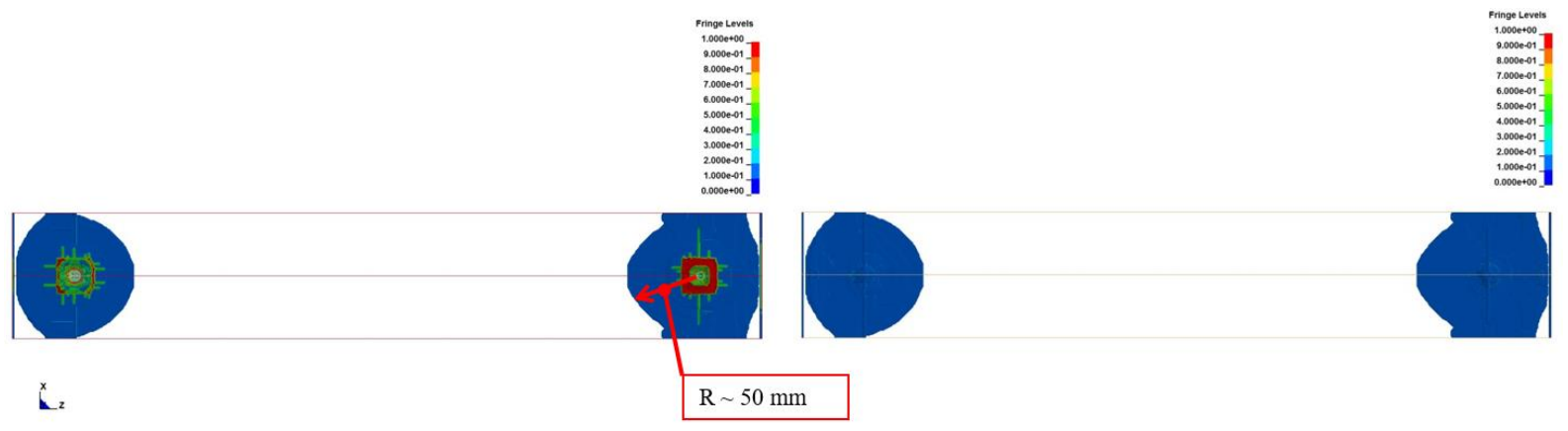

Fig. 14 Armour failure (front side - left) - the first hit on the left, the second hit on the right; armour failure (rear side - right) - the first hit on the left, the second hit on the right. 


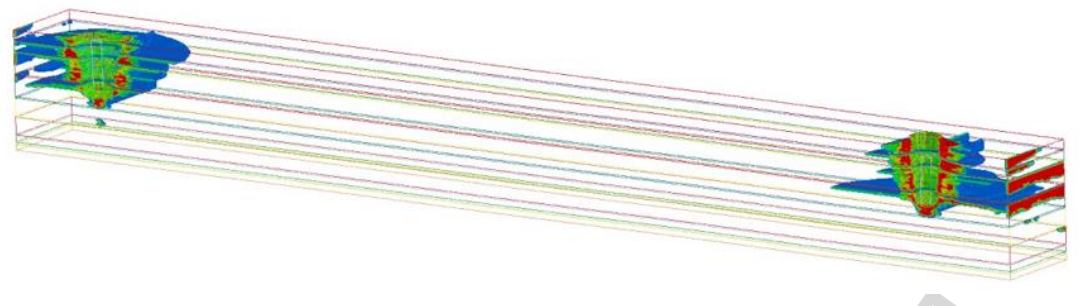

Fig. 15 Transparent armour damage at the temperature of $-32{ }^{\circ} \mathrm{C}$. 


\subsubsection{Protection Level $\mathrm{K} 3$ at the temperature of $+55^{\circ} \mathrm{C}$}

In the Fig. 16 below, the projectile interaction with transparent armour in relation to time is shown at the constant temperature of $+55^{\circ} \mathrm{C}$. 


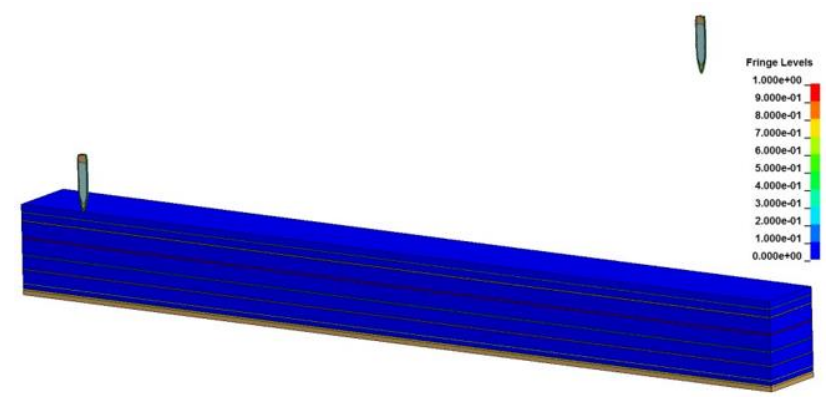

Time $=0.00 \mathrm{~s}$

Time $=0.05 \mathrm{~s}$

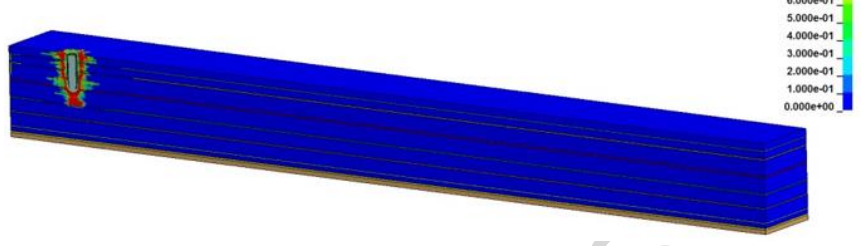

Time $=0.15 \mathrm{~s}$

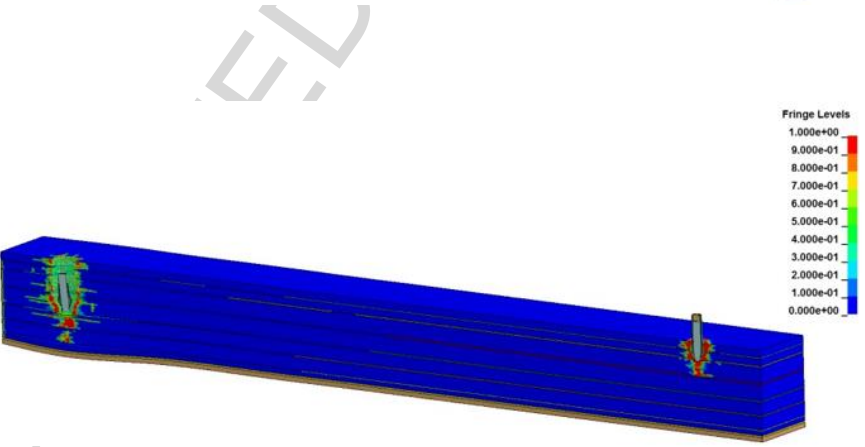

Time $=0.20 \mathrm{~s}$

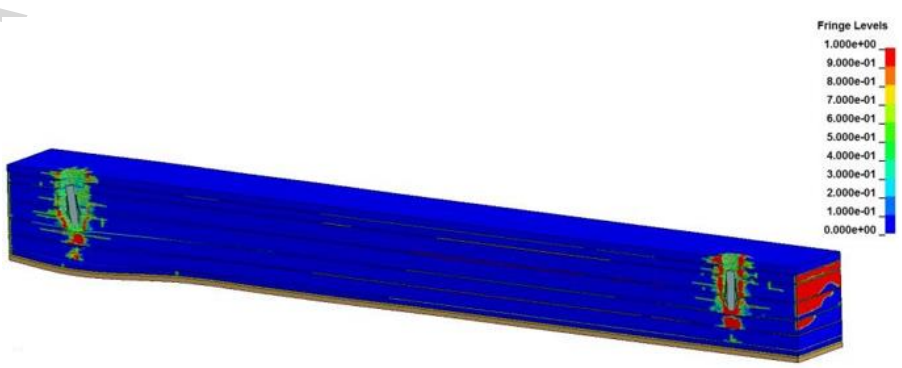

Time $=0.25 \mathrm{~s}$ 


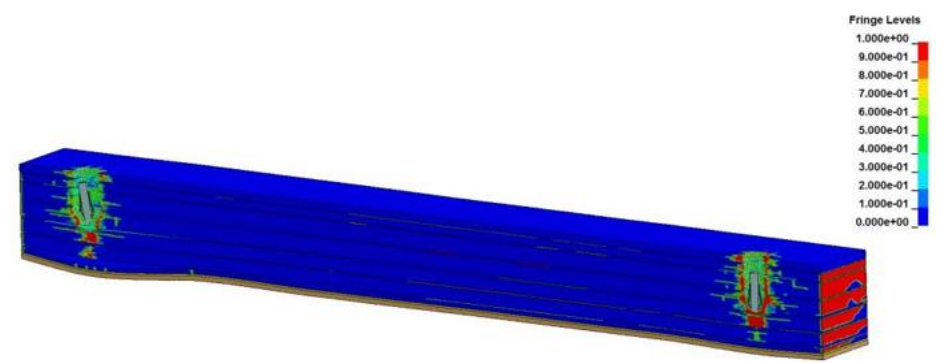

Time $=0.30 \mathrm{~s}$

Fig. 16 The course of projectile penetration into transparent armour at the temperature of $+55^{\circ} \mathrm{C}$ at different instants of time. 
It follows from the results of the numerical simulation that both the first and the second projectile stopped in the fourth layer of the armour. The depth of penetration of the first hit was $38 \mathrm{~mm}$ and of the second hit $36 \mathrm{~mm}$, Fig. 17 and 18 . 


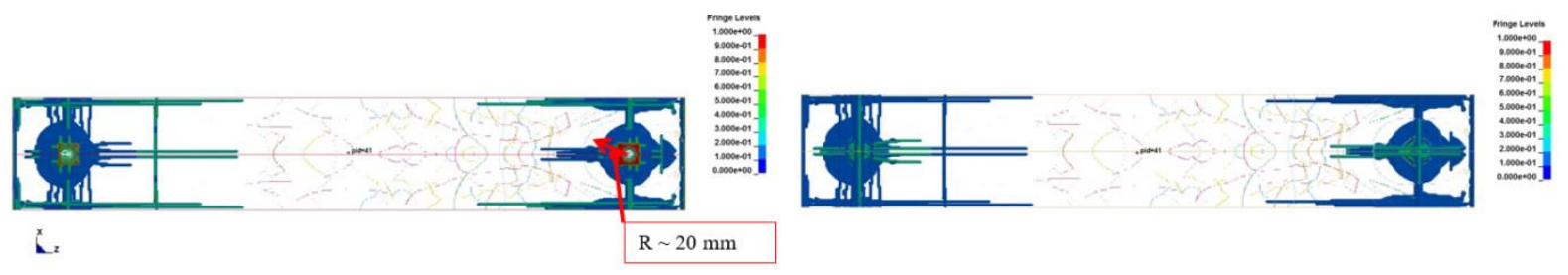

Fig. 17 Armour failure (front side - left) - the first hit on the left, the second hit on the right; armour failure (rear side - right) - the first hit on the left, the second hit on the right. 


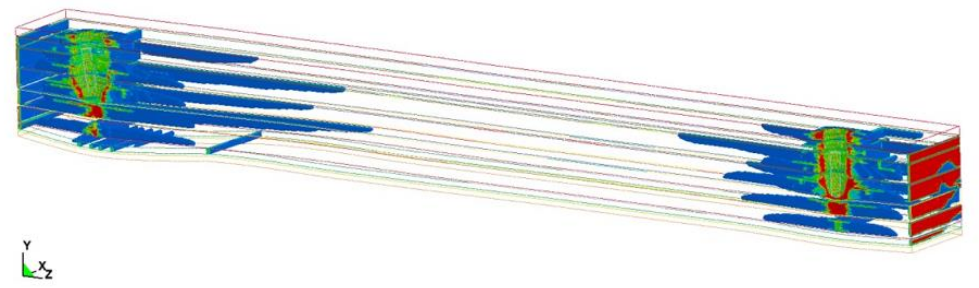

Fig. 18 The transparent armour failure at the temperature of $+55^{\circ} \mathrm{C}$. 
It follows from the results of the numerical simulation that the projectiles stopped in the third and fourth layer of the armour. The depths of individual penetrations are stated in Tab 4 below. 
TAB. 4 The depth of the projectile penetration

\begin{tabular}{|c|c|c|}
\hline \multirow{2}{*}{\begin{tabular}{c} 
Armour temperature $\left[{ }^{\circ} \mathbf{C}\right]$ \\
\cline { 2 - 3 }
\end{tabular}} & $\begin{array}{r}\text { The depth of projectile penetration into Dingo vehicle } \\
\text { transparent armour [mm] }\end{array}$ \\
\cline { 2 - 3 } & 21 & Protection Level K3 \\
\hline-32 & 24 & 30 \\
\hline+55 & Protection Level K2 & 37 \\
\hline
\end{tabular}




\section{Conclusion}

In the paper, findings obtained by the testing of properties of special transparent armours capable of absorbing impact energy, thus damping a projectile shot are summarized. In the first stage, the strength characteristics of specimens were primarily identified. The behaviour of the respective materials was monitored under both quasi-static loading and high-speed loading using the finite element method. The numerical simulations of real elements confirmed the applicability of the materials designed for the use in protection structures enhancing the protection of civil population. The efficiency of the materials was also proved by practical tests.

With the projectile penetration, failure occurs, cracks propagate in the armour material and individual armour layers are delaminated. The comparison of the results shows considerable dependence of the PVB material strength on temperature. At the temperature of $+55{ }^{\circ} \mathrm{C}$, the delamination of individual layers occurs in all the variants leading to greater deformation of the rear layer. At the temperature of $-32{ }^{\circ} \mathrm{C}$, the scope of damage is smaller if compared to the other temperatures under consideration.

The numerical simulation of the effect of projectile interaction on the life cycle of transparent armour helped understand the behaviour of transparent armours composed of multiple layers under various climatic conditions, which may lead to the elimination of risk arising from a projectile hit.

\section{Acknowledgements}

The work was supported by the Ministry of Defence of the Czech Republic project No. DZRO K-109 and project. No. OFVVU20140001 and project. No. TP 6/2017: Defectoscopic quality assessment of technical and organic materials; financed by IGA AF MENDELU. This research work has been carried out in the Centre for Research and Utilization of Renewable Energy (CVVOZE). Authors gratefully acknowledge financial support from the Ministry of Education, Youth and Sports of the Czech Republic under NPU I programme (project No. LO1210). 


\section{Reference}

1. BUCHAR, Jaroslav, VOLDŘICH, Josef. Terminální balistika (Terminal Ballistic). Prague: Academia, 2003. 340 p. ISBN 80-1222-2.

2. Stephen J., Maria HX Qin and Phillip S. Davies, High-performance laminated glass for structurally efficient glazing, Innovative Light-weight Structures and Sustainable Facades, Hong Kong, May 2008

3. JOHNSON and COOK, A constitutive model and data for metals subjected to large strains, high strain rates and high temperatures, in Proceeding of the Seventh International Ballistics Symposium, The Hague, 1983, p. 541-547

4. M. A. Iqbal, K. Senthil, V. Madhu, and N. K. Gupta, "Oblique impact on single, layered and spaced mild steel targets by 7.62 AP projectiles”, Fire Safety Journal, vol. 21, no. 1, p. $-, 2017$.

5. T. Morita, M. Beppu, M. Suzuki, M. A. Iqbal, and N. K. Gupta, “An experimental study on the temperature and structural behavior of a concrete wall exposed to fire after a highvelocity impact by a hard projectile”, Fire Safety Journal, vol. 21, no. 1, p. -, 2017.

6. Meyers and Chawla (1999): "Mechanical Behavior of Materials", 98-103.

7. McCrum, Buckley, and Bucknell (2003): "Principles of Polymer Engineering", 117-176.

8. JOHNSON and HOLMQUIST, 1994, An improved computational constitutive model for brittle materials, in Schmidt, S. C., Shaner, J. W., Samara, G. A. and Ross, M., High Pressure Science and Technology - 1993. New York: AIP Press.

9. LS-DYNA Keywords User's Manual, Volume II (Materials models), Jun 10, 2013 (revision 3372).

10. Rajput, M. A. Iqbal, and N. K. Gupta, "Ballistic performances of concrete targets subjected to long projectile impact”, Thin-Walled Structures, p. -, 2017.

11. J. Křest’an, K. Bodišová, R. Řídký, M. Popovič, R. Mikulíková, D. Kopkáně, and S. Rolc, "Armour repair optimized by means of numerical simulations", Journal of the European Ceramic Society, vol. 36, no. 12, pp. 3067-3072, 2016.

12. Zang, M. Y. and Chen, S. H. 2011. Laminated Glass. Wiley Encyclopedia of Composites. $1-7$. 


\section{Highlights}

- The data from the simulation of the projectile shot to transparent armour in an Dingo vehicle correspond with the simulation.

- Impact of the extreme temperature stress on the depth of penetration was demonstrated by measurement and simulation.

- The mechanism of deformation of the individual layers of the armour affected by extreme temperatures stress was described by simulation. 